\title{
Development of Software and Hardware Complex based on Theoretical Modeling and Experimental Study of Linearly Extended Energy Facilities on their Technical Condition
}

\author{
${ }^{1}$ Sergey A. Nazarychev, ${ }^{2}$ Sergey O. Gaponenko, ${ }^{3}$ Rozalina Z. Shakurova \\ ${ }^{1}$ Kazan Federal University, Russia \\ 2,3 Kazan State Power Engineering University, Russia \\ Email:sogaponenko@yandex.ru,shakurova.rz@gmail.com
}

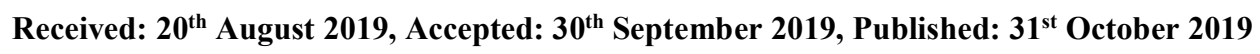

\begin{abstract}
One of the key areas of development of the Russian economy is to increase energy efficiency, according to the Energy Strategy of Russia for the period until 2030. Our country has a huge potential for energy conservation, and its implementation will significantly reduce the energy intensity of the country's GDP without increasing energy capacity, thus contributing to the economic growth. Currently, the maximum reserve of energy saving accounts for the industry, housing and communal services. A large amount of energy is consumed in these sectors, but most of it is spent irrationally. At the same time, a large amount of energy is lost during its distribution and transportation. The main reason is the high degree of wear and tear of equipment for the energy supply systems. Most of the main pipelines and equipment of energy systems have been in operation for over 30 years and are currently in poor condition. Due to the fact that the work of most industrial enterprises, housing and communal services and other sectors of the economy directly depends on the reliable and uninterrupted operation of energy systems, it becomes extremely important to maintain equipment and energy distribution systems in operable condition. The task is achieved by regularly diagnosing the technical condition of the equipment during transportation of energy carriers. In order to increase energy efficiency and reliability of energy transportation systems, we built the mathematical models of pipes of various geometric sizes and diameters for modeling soil pressure, developed an information technology complex, and conducted some laboratory tests within this work.
\end{abstract}

\section{Keywords}

Energy Conservation, Energy Carrier, Non-Destructive Testing, Mathematical Model, Soil Effect, Acoustic Vibrations.

\section{Introduction}

On November 23, 2009, the Federal Law of the Russian Federation No. 261-FZ "On Energy Saving and Improving Energy Efficiency..." was adopted. It is aimed at efficient and rational use of energy resources, as well as supporting and stimulating energy conservation and increasing energy efficiency [1-5].

Russia has great potential for energy conservation, the implementation of which allows reducing the energy intensity of the country's GDP without increasing energy capacities, thus contributing to the country's economic growth.

Currently, the maximum reserve of energy saving accounts for the industry, housing and communal services. At the same time, a large amount of energy is lost during its distribution and transportation.Energy losses in heating systems reach $60 \%$ (while this figure is much lower and amounts to $2-10 \%$ in European countries) [6-9].

One of the main reasons for such high energy losses is the high wear and tear of the energy transportation and distribution systems. The destruction of pipelines occurs due to the appearance of local defects in the walls of the pipe during the construction and operation, which subsequently causes not only energy leakage, heat loss, but more importantly, causes accidents that entail large material costs, significant environmental damage, and sometimes even human sacrifice $[10,11]$.

In this regard, tight control and regular monitoring of the technical condition of pipelines and equipment of energy transportation systems is necessary. Improvement of the reliability of equipment and energy supply systems is carried out both at the design stage and at the operation stage. For this purpose, the mathematical modeling methods have long been used. Their use can significantly increase the reliability of diagnosis. In this work, we constructed the models of pipelines of various geometric sizes and materials in the ANSYS finite element analysis software package [12, 13]. Then, we simulated the effect of various types of soil on the pipeline at different depths. The calculated values of the pressure of various types of soil from the depth are presented in Table 1. 


\begin{tabular}{|l|c|l|l|l|c|}
\hline $\begin{array}{c}\text { Soil } \\
\text { type }\end{array}$ & $\begin{array}{l}\text { Pressure, } \mathrm{kN} / \mathrm{m}^{2} \\
\text { (depth 0.7 m) }\end{array}$ & $\begin{array}{l}\text { Pressure, } \\
\mathrm{kN} / \mathrm{m}^{2} \\
(\text { depth } 1 \mathrm{~m})\end{array}$ & $\begin{array}{l}\text { Pressure, } \\
\mathrm{kN} / \mathrm{m}^{2} \\
(\text { depth } 1.3 \mathrm{~m})\end{array}$ & $\begin{array}{l}\text { Pressure, } \\
\mathrm{kN} / \mathrm{m}^{2} \\
(\text { depth 2 m) }\end{array}$ & $\begin{array}{l}\text { Pressure, } \mathrm{kN} / \mathrm{m}^{2} \\
\text { (depth 2.5 m) }\end{array}$ \\
\hline Fine sands & 27.418 & 39.243 & 51.068 & 78.659 & 98.366 \\
\hline Dusty sands & 29.063 & 41.597 & 54.131 & 83.378 & 104.268 \\
\hline Clay & 30.543 & 43.715 & 56.889 & 87.623 & 109.578 \\
\hline Loam & 30.49 & 43.7 & 56.888 & 87.624 & 109.57 \\
\hline Heavy clay & 31.2 & 44.66 & 58.112 & 89.509 & 111.935 \\
\hline
\end{tabular}

Table 1: The Calculated Values of the Pressure of Various Types of Soil from the Depth.

Type of soil and various depths of the pipeline were modeled by applying the calculated pressure on its walls (Fig. 1).

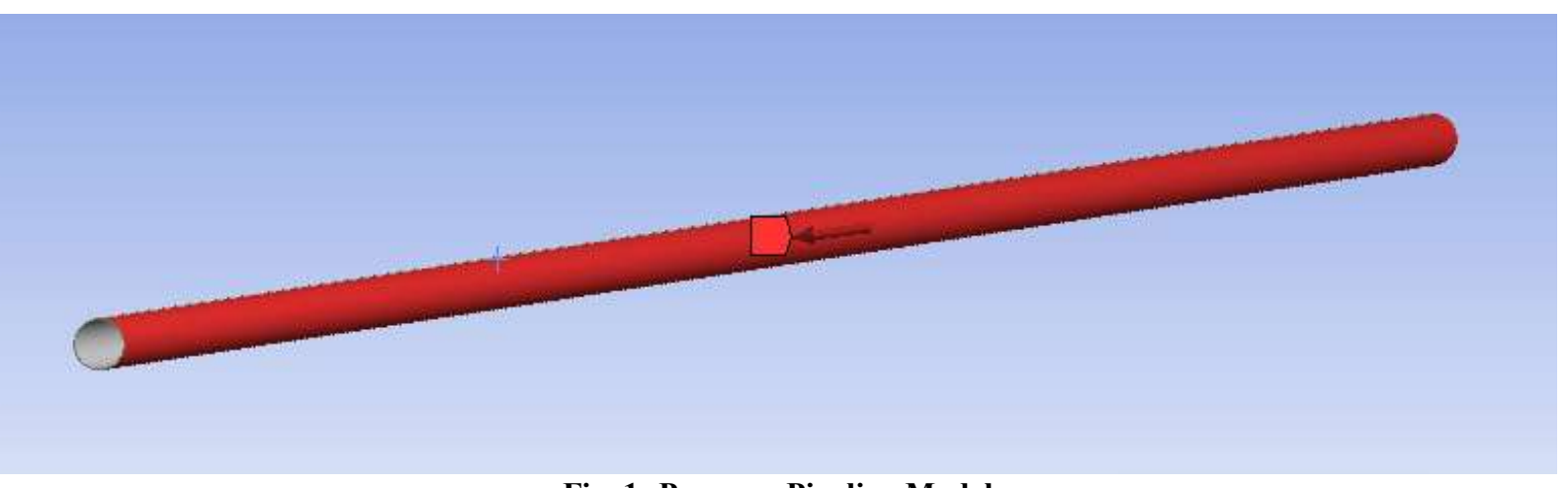

Fig. 1: Pressure Pipeline Model

The results of a harmonic analysis of pipelines of various materials and geometric dimensions are presented in Figures $2-5$.

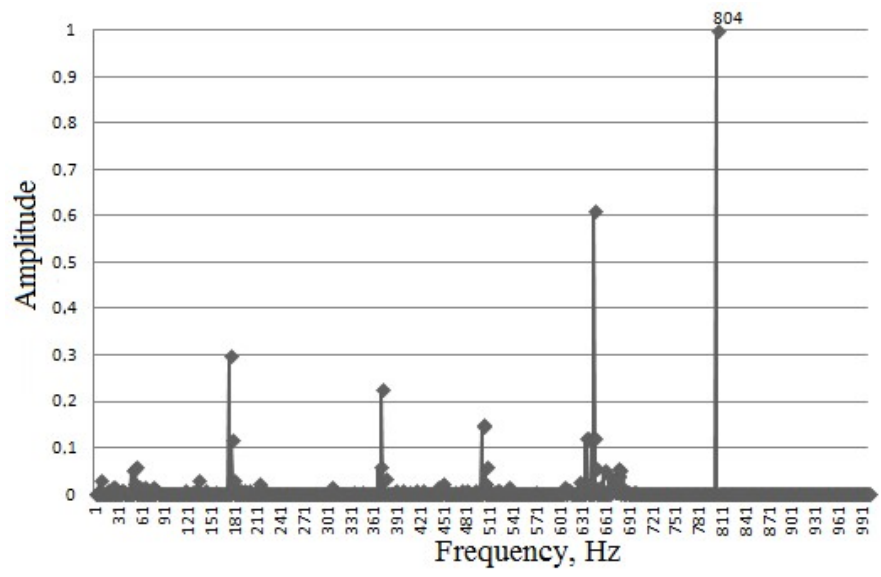

Fig. 2: The Results of a Harmonic Analysis of a Steel Pipeline 2000x110x2.2 (Length 2000 mm, Diameter $110 \mathrm{~mm}$, Wall Thickness $2.2 \mathrm{~mm}$ ) 


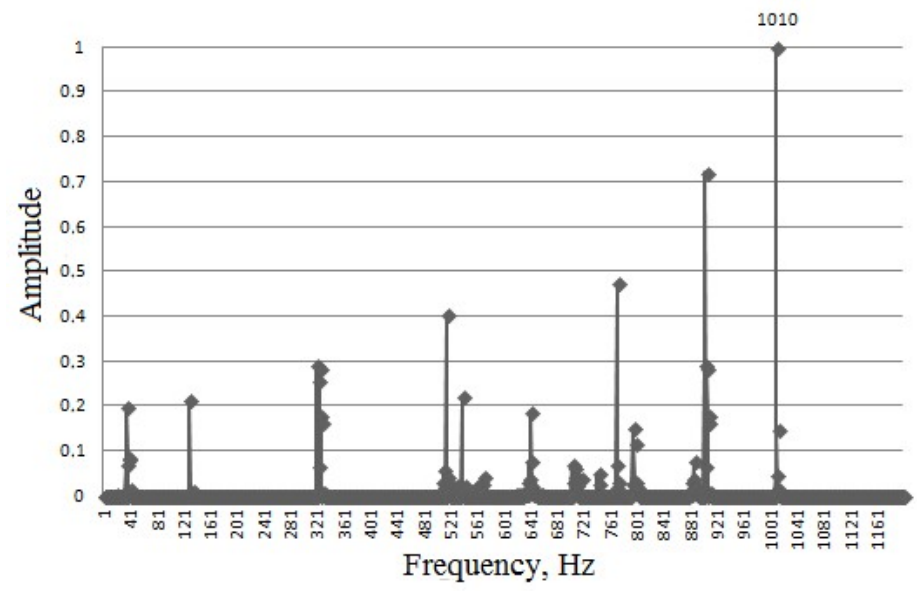

Fig. 3: The Result of a Harmonic Analysis of the Pipeline 5000x40x6 made of Polypropylene

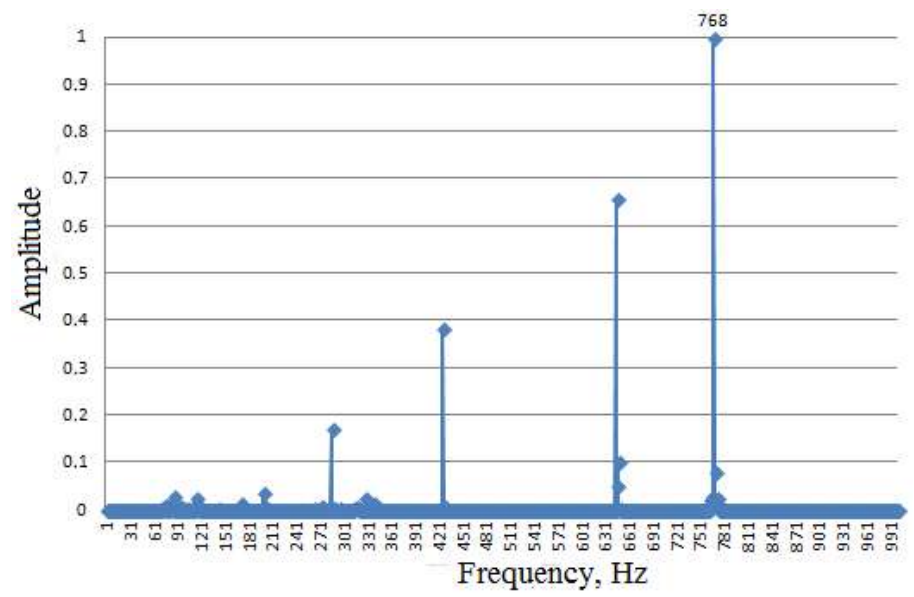

Fig. 4: The Result of a Harmonic Analysis of the Pipeline 8000x125x3.1 made of Polyethylene

\section{Methods}

Non-destructive testing methods are used to diagnose the technical condition of various equipment and pipelines, a feature of which is equipment diagnostics during its operation, and the currently used monitoring methods and tools make it possible to accurately identify a defect, its type, size and location. However, in practice, several methods of non-destructive testing are used to determine technical condition of an object, each of which is able to detect only defects of a certain type. In this regard, there is a need to modernize control methods and techniques [14-18]. For this purpose, we developed and created an information-diagnostic complex shown in Figure 5.

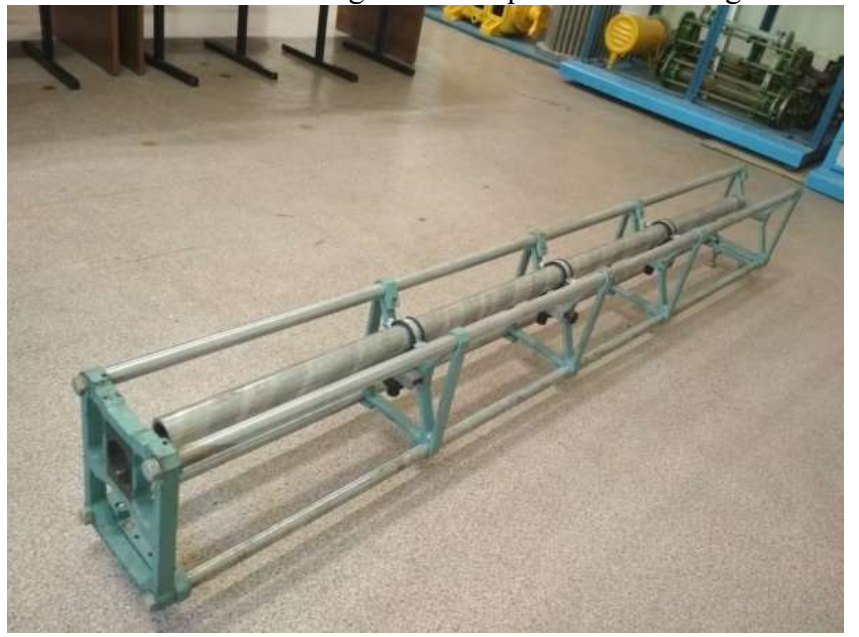

Fig. 5: Information-Diagnostic Complex

(1 - Guide; 2 - Support with a Clamp; 3 - Support with an Acoustic Emitter; 4 - Test Pipe; 5 - Base with Legs) 
The information-diagnostic complex is a support system with clamps, on which the pipeline selected as the control object is attached. The complex also includes an excitation system consisting of an excitation device shown in Figure 6 and a recording system consisting of a sensitive element and analog-to-digital converter connected to a personal computer by electrical communication.

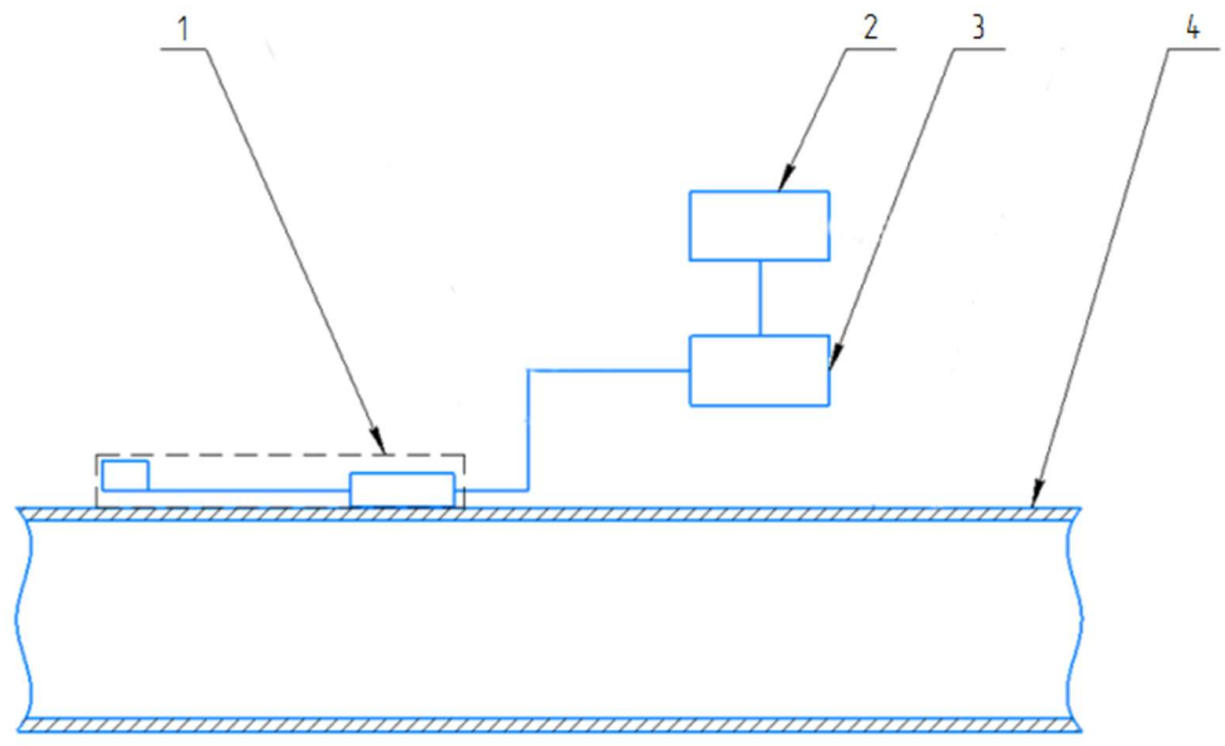

Fig. 6: Information-Diagnostic Complex

(1 - Inertial Resonator, 2 -Ppersonal Computer; 3 - Digital-to-Analog Converter; 4 - Test Pipeline)

The principle of the information-diagnostic complex is as follows:

an excitation device is attached to the pipeline, using a personal digital-to-analog converter computer, this device is activated, it exerts a vibrational effect on the pipeline wall under study, then, using a sensitive element made in the form of a microphone, the vibrational parameters of the pipeline walls are measured, and the information obtained through the analog-to-digital converter enters a personal computer for registration and further analysis.

To control the vibrational impact on the pipeline under study, as well as to collect, store and process signals from a microphone, we developed the LabVIEW condition monitoring system program. Figure 7 shows the panel of the "Generation" program, in which the speed of the inertial resonator can be controlled and adjusted. Figure 8 shows the panel of the "Registration" program, in which the signals from the microphone are registered and these signals are converted into a spectrum for further analysis.

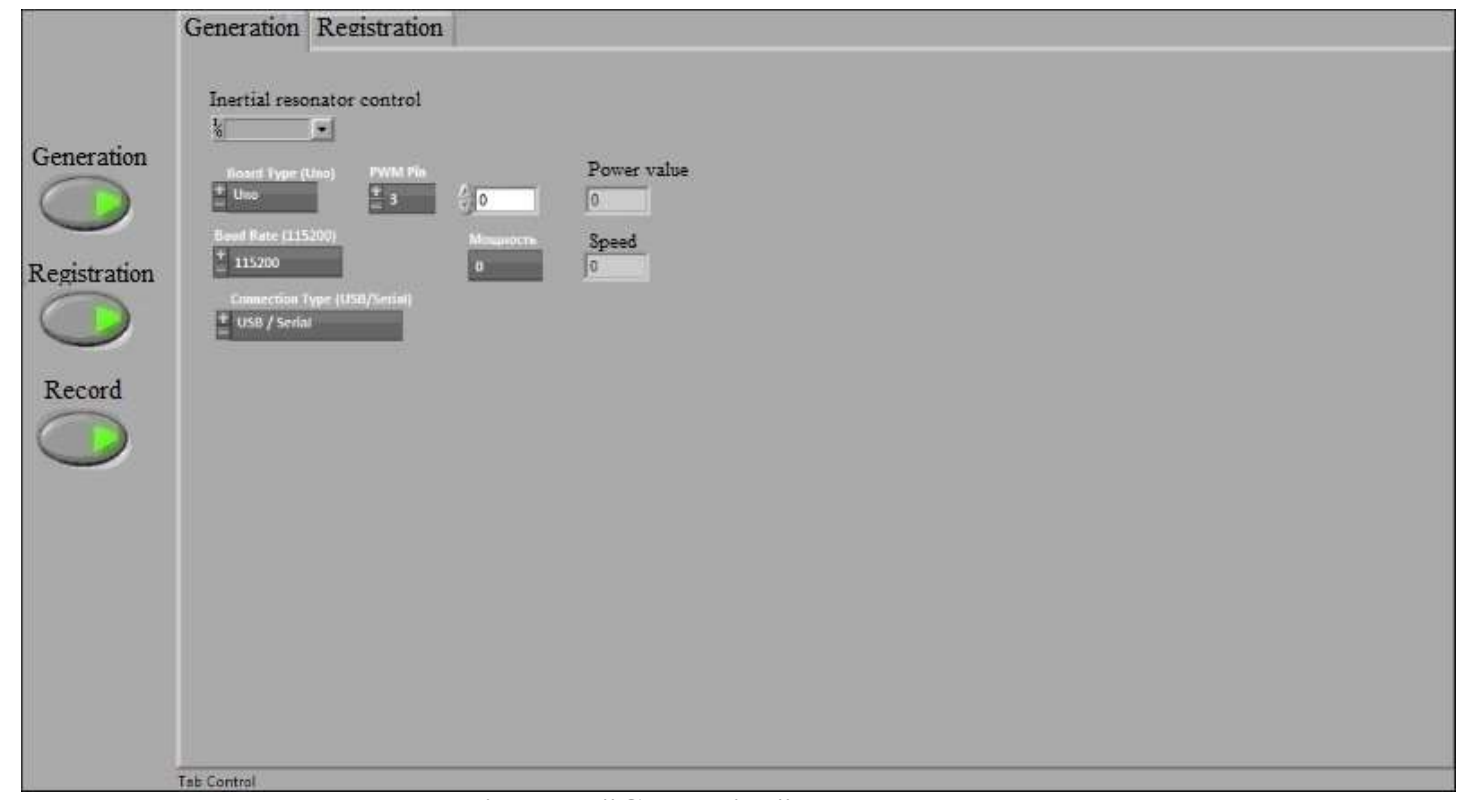

Figure 7: "Generation" Program Panel 


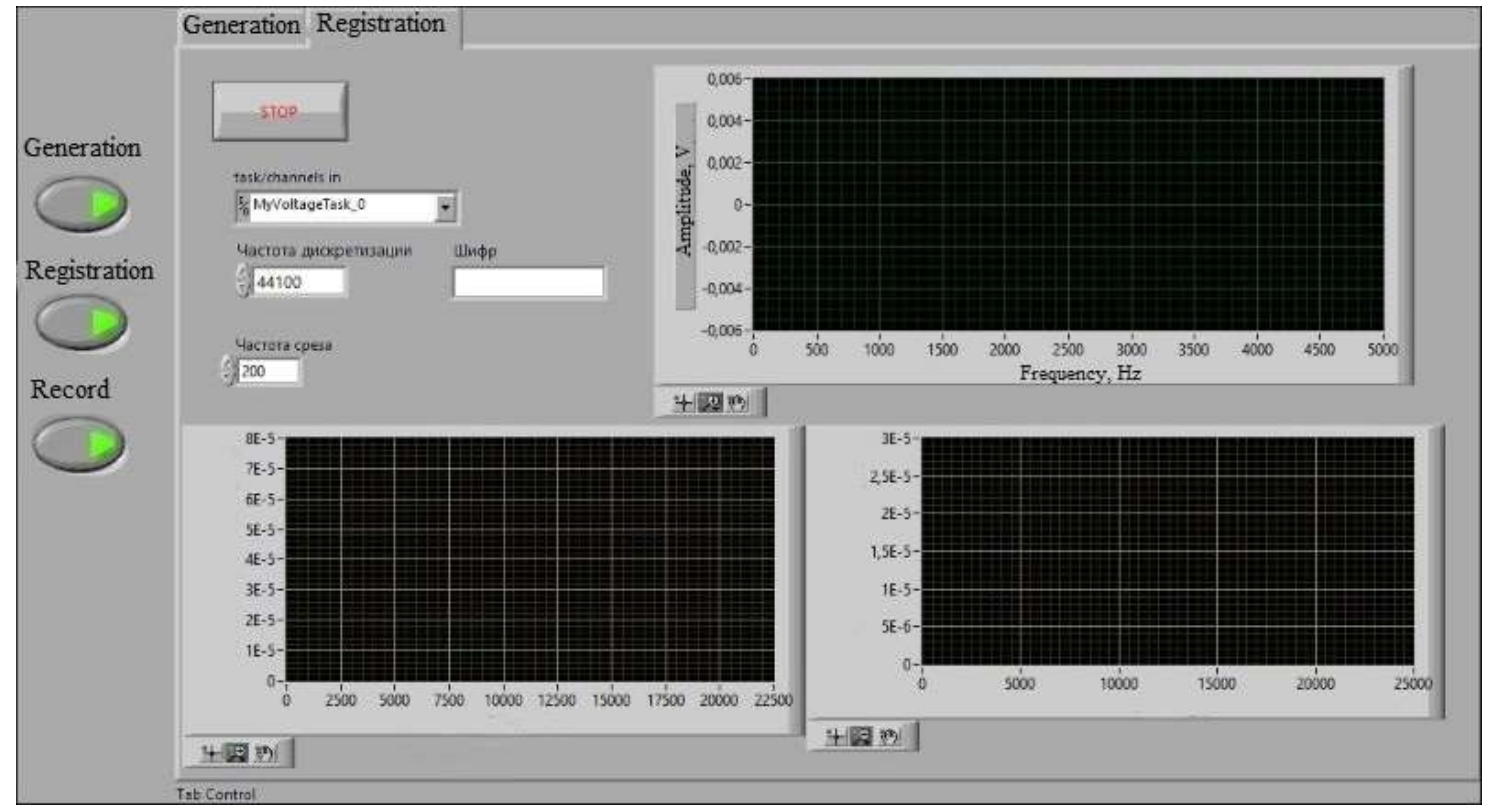

Figure 8: "Registration" Program Panel

Determination of natural frequencies of vibration of the information-diagnostic complex (IDC) to monitor the technical condition of equipment

As a result of the study, the vibrational modes of the IDC are determined. When analyzing the results of modal calculation, it is necessary to take into account that the form of free vibrations was calculated in relative units and did not allow determining the absolute displacements.

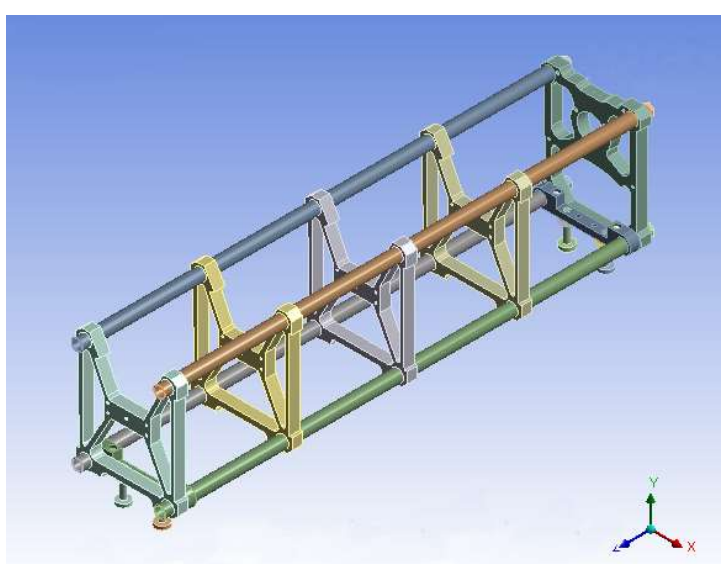

Fig. 9: Imported Model

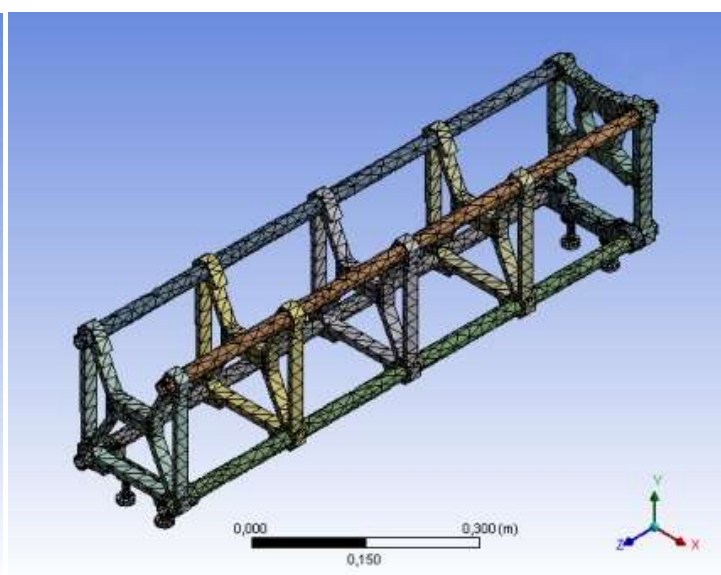

Fig. 10: Finite Element Mesh

Material properties:

- $\quad$ density: $7,800 \mathrm{~kg} / \mathrm{m}^{3}$;

- $\quad$ elastic modulus: $2.17 \cdot 10^{-5} \mathrm{MPa}$;

- $\quad$ Poisson's ratio: 0.29;

Contact conditions: floor surface

Grid of finite elements (Fig. 10).

- mesh type: solid mesh;

- $\quad$ shard used: standard mesh;

- mesh quality: high;

- $\quad$ number of nodes: 110974 ;

- $\quad$ number of elements: 32649.

The results are presented in Table 2. 


\begin{tabular}{|c|c|c|c|}
\hline Vibration mode number & Frequency, $\mathrm{Hz}$ & Vibration mode number & Frequency, $\mathrm{Hz}$ \\
\hline 1 & 92.848 & 26 & 1014.3 \\
\hline 2 & 142.05 & 27 & 1028.3 \\
\hline 3 & 166.21 & 28 & 1063.1 \\
\hline 4 & 173.32 & 29 & 1119.7 \\
\hline 5 & 188.1 & 30 & 1140.7 \\
\hline 6 & 262.38 & 31 & 1175 \\
\hline 7 & 322.11 & 32 & 1220.8 \\
\hline 8 & 337.9 & 33 & 1262.6 \\
\hline 9 & 391.28 & 34 & 1268.2 \\
\hline 10 & 424.07 & 35 & 1284.8 \\
\hline 11 & 483.53 & 36 & 1325.8 \\
\hline 12 & 544.85 & 37 & 1331.4 \\
\hline 13 & 574.89 & 38 & 1396.9 \\
\hline 14 & 622.84 & 39 & 1424 \\
\hline 15 & 738.09 & 40 & 1438.6 \\
\hline 16 & 742.57 & 41 & 1441.5 \\
\hline 17 & 749.35 & 42 & 1456.6 \\
\hline 18 & 774.17 & 43 & 1484.8 \\
\hline 19 & 828.85 & 44 & 1502.7 \\
\hline 20 & 849.66 & 45 & 1541.3 \\
\hline 21 & 876.57 & 46 & 1555.6 \\
\hline 22 & 880.31 & 47 & 1609.1 \\
\hline 23 & 921.44 & 48 & 1616 \\
\hline 24 & 948.73 & 49 & 1638.6 \\
\hline 25 & 955.44 & 50 & 1661.7 \\
\hline
\end{tabular}

Table 2: Calculation Results

The vibration form of the fifteenth mode of the investigated setup at a frequency of $738.09 \mathrm{~Hz}$ is shown in Figure 11.

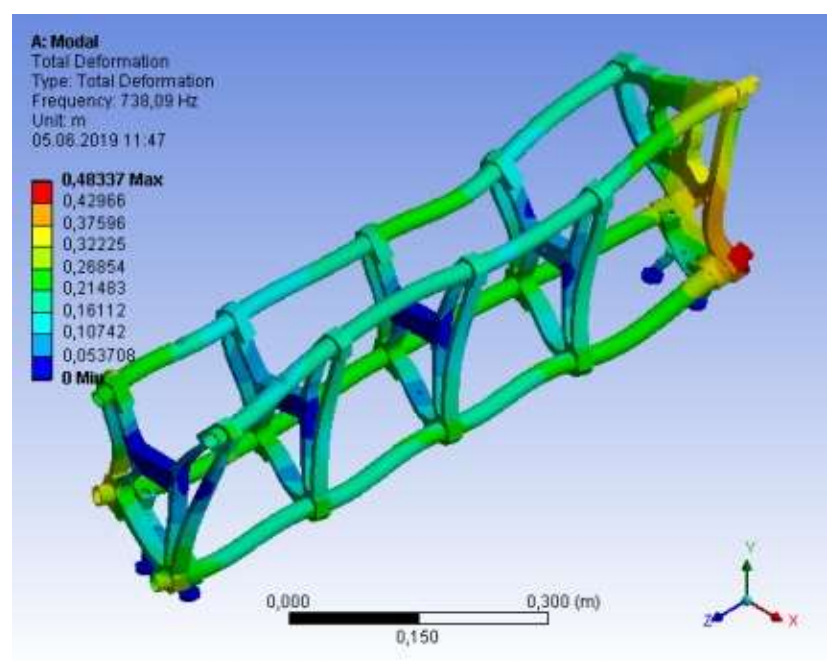

Fig. 11: Vibration form at a Frequency of $738.09 \mathrm{~Hz}$.

\section{Results and Discussion}

During the experiment, an inertial resonator with a rotation frequency of $15,000 \mathrm{rpm}$ and an operating voltage of $3 \mathrm{~V}$ was used to excite vibrations in the wall of the studied pipeline. The speed adjustment of the inertial resonator motor is implemented on the Arduino Uno platform.

The generated frequencies were recorded by a microphone. Figures 12 and 13 show photographs of a laboratory plant. 


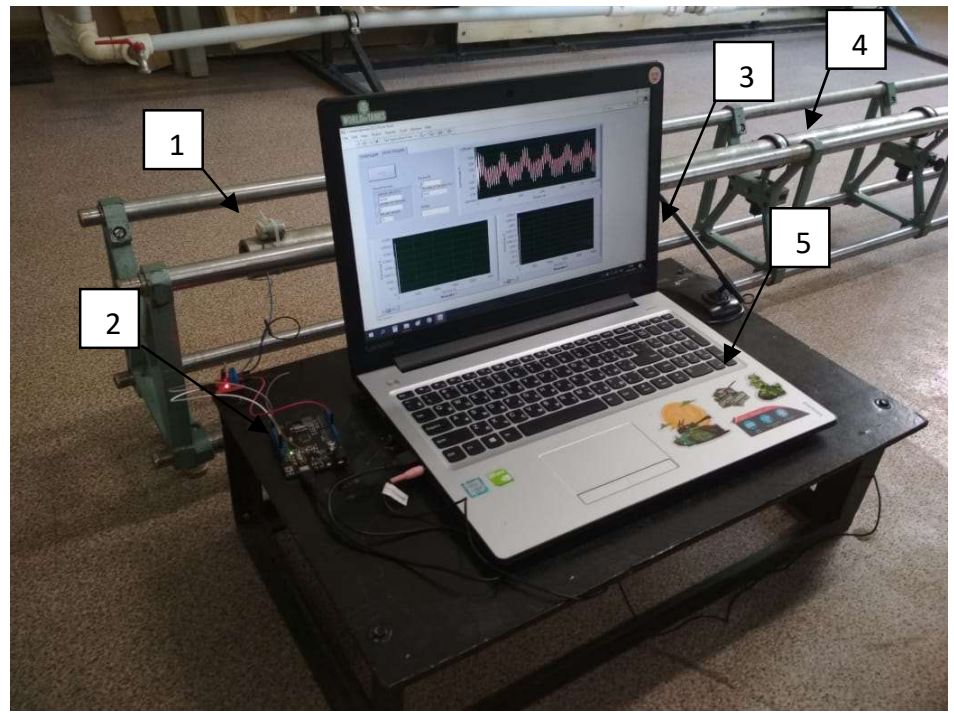

Figure 12. Photo of the Laboratory Plant (Main View)

(1 - Inertial Resonator; 2 - Arduino Uno Board; 3 - Microphone; 4 - Investigated Pipeline; 5 - Personal Computer)

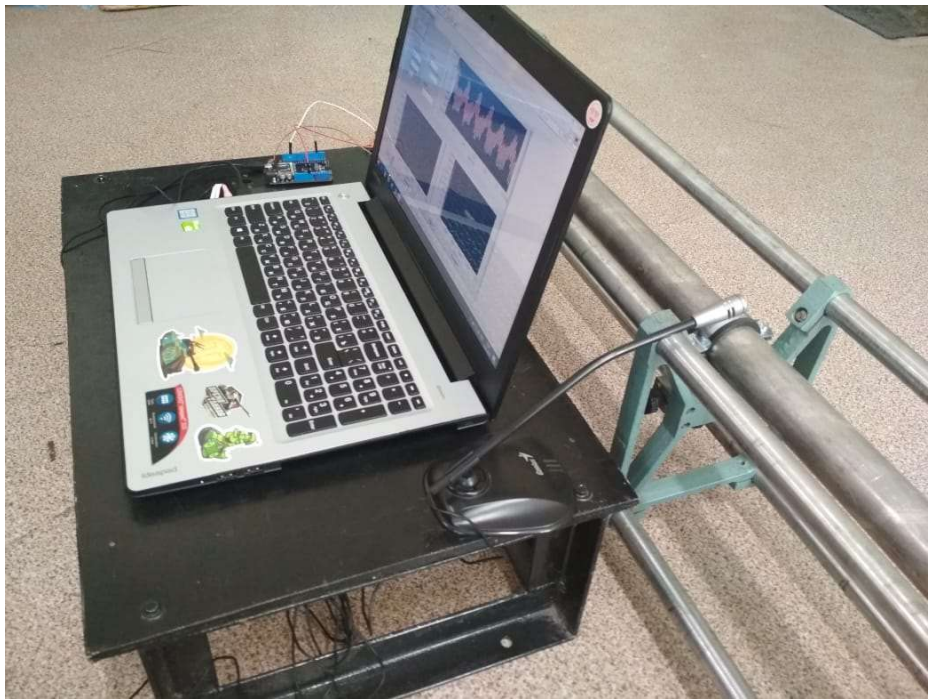

Figure 13: Plant Photo (Left View)

The initial frequency of rotation of the inertial resonator is $100 \mathrm{~Hz}$, the measurement step is $10 \mathrm{~Hz}$; after $250 \mathrm{~Hz}$, the measurement step is $5 \mathrm{~Hz}$. Static and random error was $10 \%$.

In the graphs, the amplitude in $\mathrm{mV}$ is plotted along the vertical axis, and the frequency in $\mathrm{Hz}$ - along the horizontal axis The measurement results at some frequencies are presented in Figures 14-19.

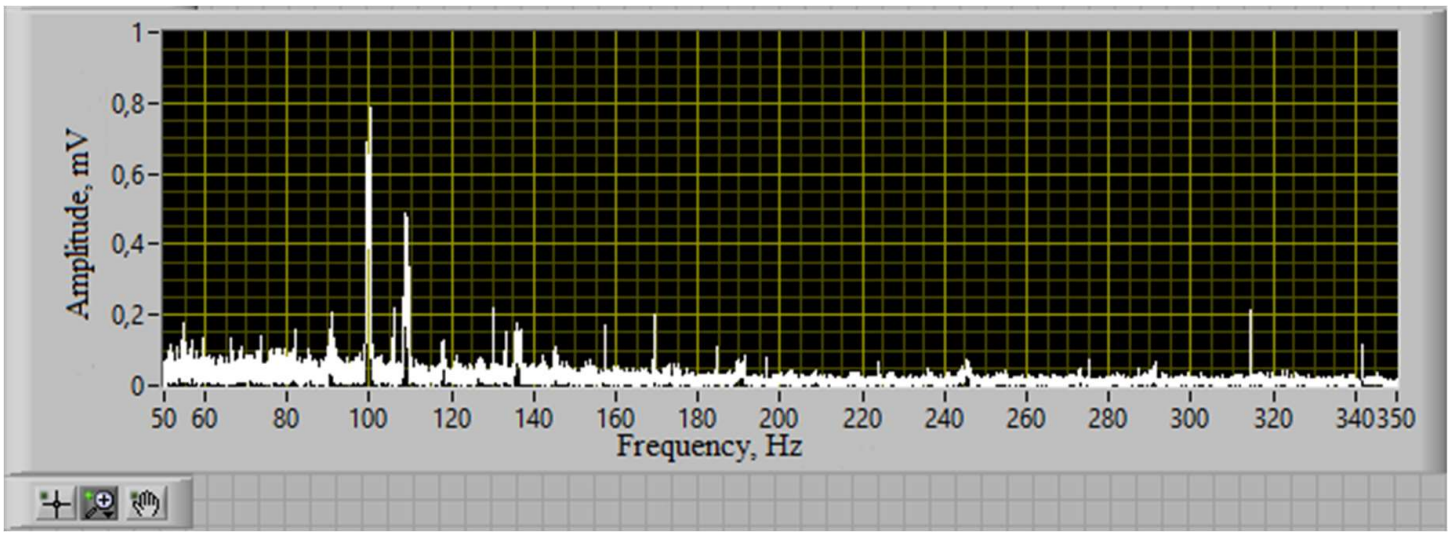

Figure 14: Excitation Frequency is $100 \mathrm{~Hz}$. 


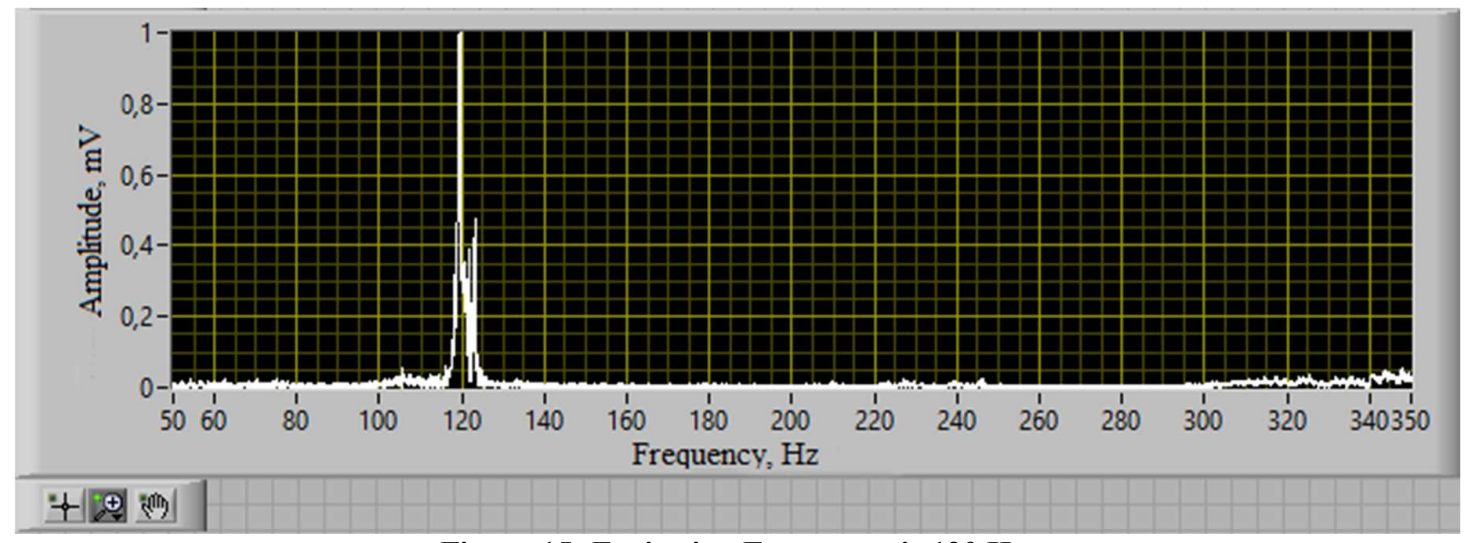

Figure 15: Excitation Frequency is $120 \mathrm{~Hz}$.

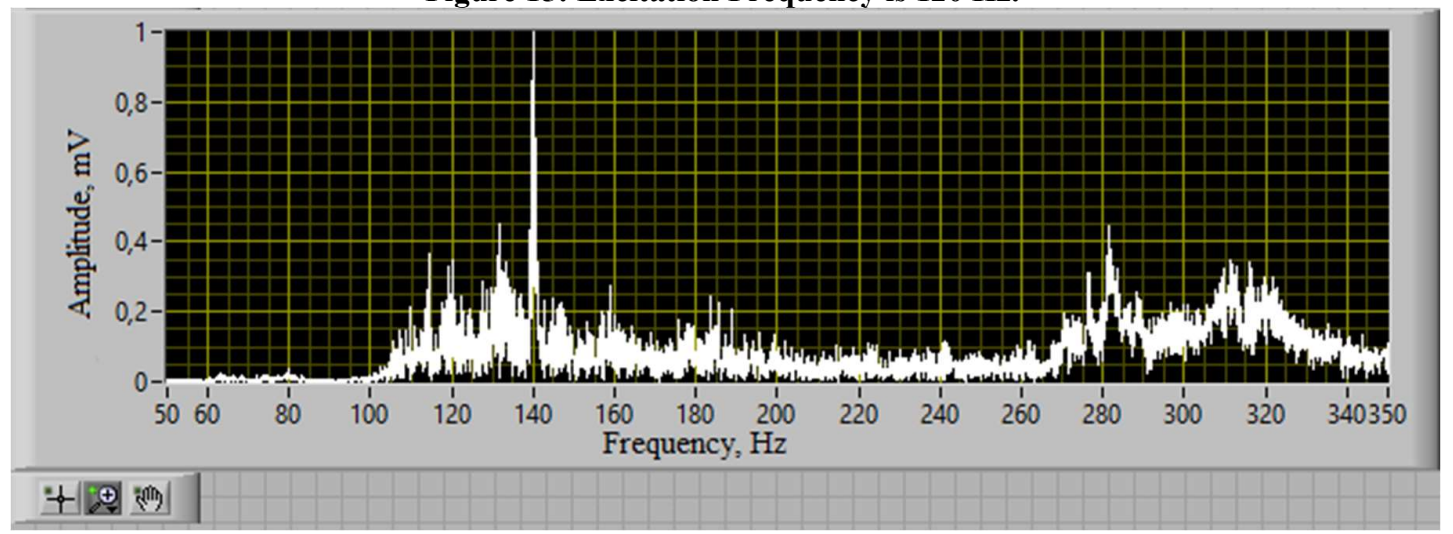

Figure 16: Excitation Frequency is $140 \mathrm{~Hz}$.

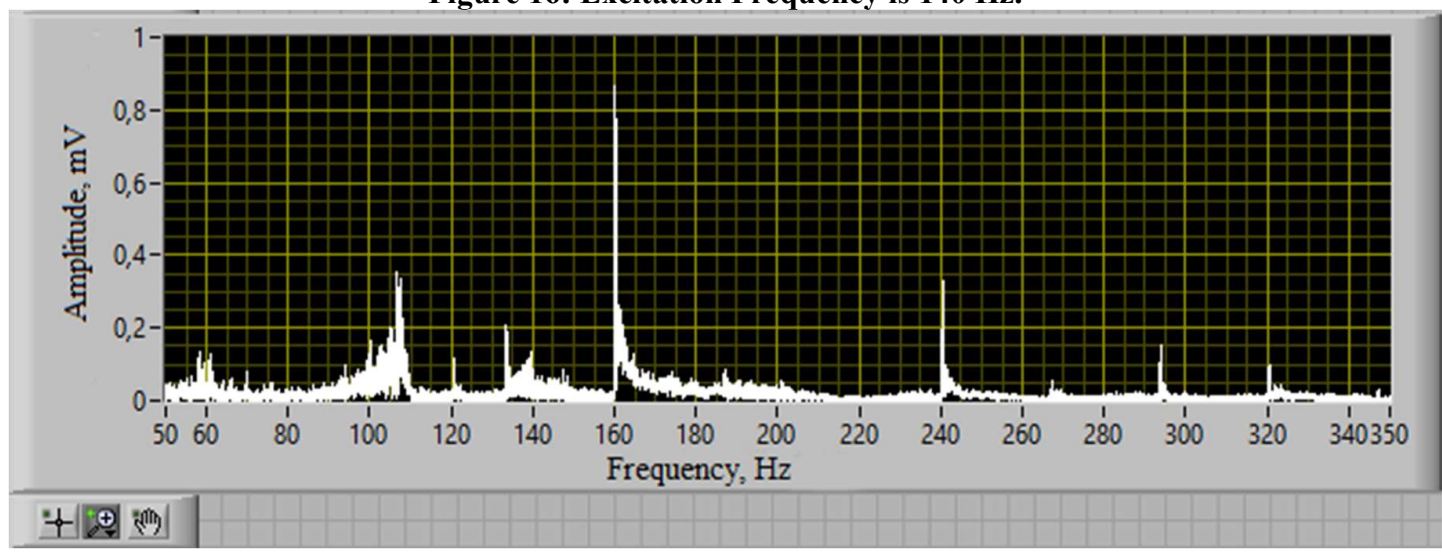

Figure 17: Excitation Frequency is $160 \mathrm{~Hz}$.

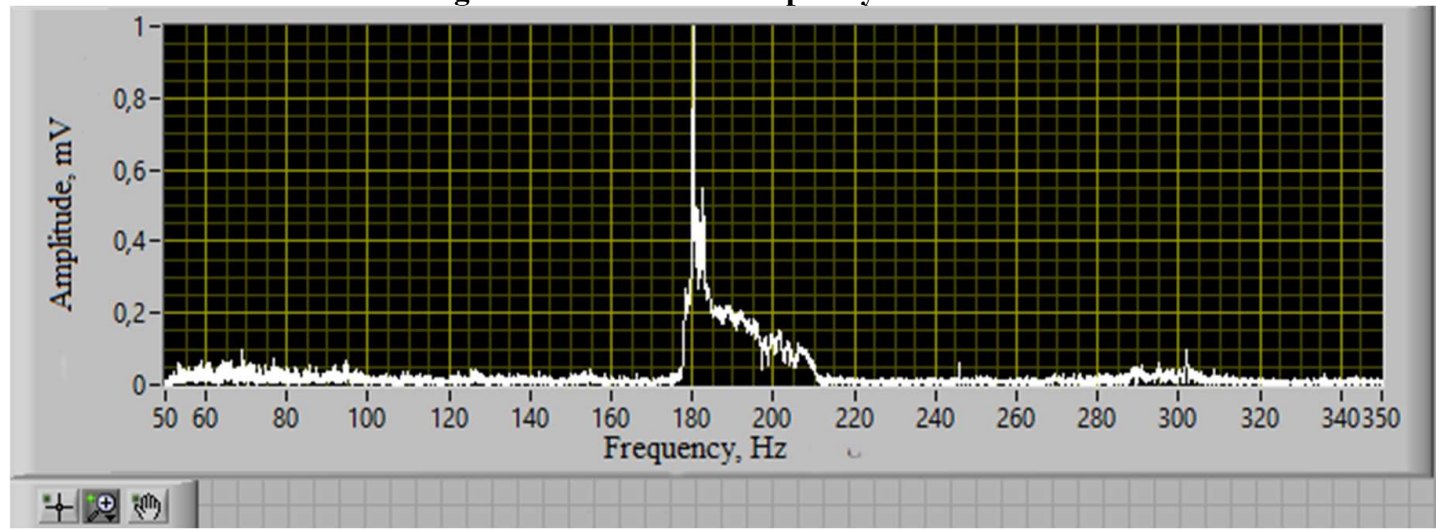

Figure 18: Excitation Frequency is $180 \mathrm{~Hz}$. 


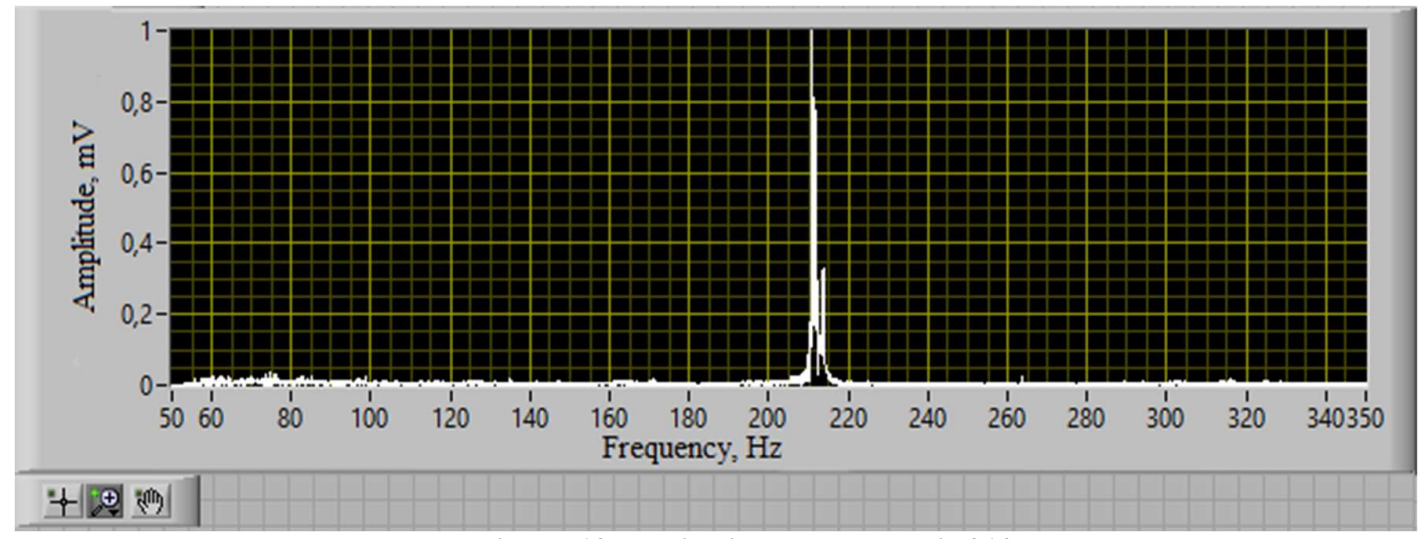

Figure 19: Excitation Frequency is $210 \mathrm{~Hz}$.

\section{Summary}

As a result of this work, a reliable and energy-efficient device for diagnosing power equipment and a computer program "Contactless monitoring system" were developed to monitor the device operation and analyze the data obtained.

In combination with other non-destructive testing methods, the developed technique is applicable to increase the efficiency and reliability of assessing the technical condition of equipment.

\section{Conclusions}

In the future, it is planned to conduct a series of laboratory tests on pipelines of various sections, diameters, consisting of different materials. Mathematical modeling of the pipeline under the influence of various types of soil and at different depths will improve the reliability of their work. The developed technique for the diagnosis of equipment and pipelines of energy systems will significantly improve the efficiency of energy supply.

\section{Acknowledgements}

The work is performed according to the Russian Government Program of Competitive Growth of Kazan Federal University.

\section{References}

[1] Gaponenko, S.O. Acoustic-resonance information-measuring complex and methods for controlling the location of buried pipelines: Abstract of a Thesis of the Candidate of Technical Sciences / Kazan State Power Engineering University, Kazan, 2017. - 22 p.

[2] Gaponenko, S.O. Model plant for developing a method for determining the location of hidden pipelines / S.O. Gaponenko, A.E. Kondratiev // News of the Higher Educational Institutions. Energy Issues. - Kazan: KSPEU. 2014. - No. 7-8. - P. 123-129.

[3] Gaponenko, S.O. Promising methods and techniques for searching for hidden channels, cavities and pipelines by vibroacoustic method / S.O. Gaponenko, A.E. Kondratiev // Bulletin of the North Caucasus Federal University. Stavropol: SKFU. - 2015. - No. 2(47). - P. 9-13.

[4] Kondratiev, A.E. Measuring and diagnostic complex for determining the location of hidden pipelines / S.O. Gaponenko, A.E. Kondratiev // News of the Higher Educational Institutions. Energy Issues. - Kazan: KSPEU. 2013. - No. 3-4. - P. 138-141.

[5] Gaponenko, S.O. Mathematical modeling of vibrations of an elastic shell under the influence of ground / S.O. Gaponenko, A.E. Kondratiev, A.A. Ibadov // International Science and Technology Conference "EastConf", EastConf 2019, IEEE. - 2019.

[6] Gaponenko, S.O. Low-frequency vibro-acoustic method of determination of the location of the hidden canals and pipelines / S.O. Gaponenko, A.E. Kondratiev, A.R. Zagretdinov // Procedia Engineering. - 2016. - Vol. 150. - P. 2321-2326.

[7] Gaponenko, S.O. Determination of informative frequency ranges for buried pipeline location control / S.A. Nazarychev, S.O. Gaponenko, A.E. Kondratiev // Helix. - 2018. - Vol. 8(1). - P. 2481-2487.

[8] Patent No. 2482515, Russian Federation: MPK G01V1/00, G01N29/00. The method for determining pipeline location / A.E. Kondratiev, A.R. Zagretdinov, S.O. Gaponenko; Applicant and patent holder: FGBOU VPO “KSPEU” (RU). - No. 2011151380/28; declared 15.12.2011; published 20.05.2013; bull. No. 14. - 6 p.

[9] Babakov I.M. Vibration theory: training manual. - M.: Drofa, 2004. - 593 p.

[10] Timoshenko S.P. Vibrations in engineering. - M.: Fizmatgiz, 1959. - 440 p.

[11] Yurko V.A. Introduction to the theory of inverse spectral problems. M: Fizmatlit, 2007. - $384 \mathrm{p}$.

[12] Leontiev N. B. Application of the ANSYS system to solving problems of modal and harmonic analysis // Nizhny Novgorod. -2006. 
[13] Bruyaka V.A. Engineering analysis at ANSYS Workbench: study guide / V.A. Bruyaka, V.G. Fokin, E.A. Soldusova, N.A. Glazunova, I.E. Adeyanov. - Samara: Samara State Technical University, 2010. - 271 p.

[14] Gladwell G.M.L. Inverse Problems in Vibration. 2nd ed. - Dordrecht, Boston, London: Kluwer Academic Publishers, 2004. (Russian translation: Gladwell G.M.L. Inverse problems in the theory of vibrations. - M. Izhevsk: NITS "Regular and chaotic dynamics", Institute of Computer Research, 2008).

[15] Seguini M. Modeling of soil-structure interaction behaviour: geometric nonlinearity of buried structures combined to spatial variability of soil / Seguini M., Nedjar N. // European Journal of Environmental and Civil Engineering. - 2017. - Vol. 21 - I. 10. - pp. 1217-1236.

[16] Shirman A., Soloviev A. «Practical vibration diagnostics and monitoring of mechanical equipment»//Moscow.1996.-p.276.

[17] Zachwieja, J.Pipeline stress analysis under supporting structure vibrations / Zachwieja, J. // Diagnostyka. - 2017. - Vol. 18. - I. 2. - pp. 23-30.

[18] Stein, Y. Development and improvement of methods of diagnostics of heating systems in modern conditions / Stein, Y.,Zonova, N.,Kubrak, I.,Andreeva, L. // IOP Conference Series: Earth and Environmental Science. 2017. - Vol. 90. -I. 1. - Article number 012139. 